\title{
WIDENING OF INTERVERTEBRAL FORAMEN BY TORTUOUS VERTEBRAL ARTERY
}

\author{
Sergio Eiji Ono, Christiane Sayuri Kawasaki, Luiz Otávio de Mattos Coelho, \\ Fabiano Ferrari Lucaski, Arnolfo de Carvalho Neto
}

A tortuous vertebral artery is a rare entity and exceptionally causes symptoms, like radiculopathy, when it migrates into the intervertebral foramen. It must be considered in the differential diagnosis of intervertebral foramen widening, and be reported to alert surgeons, avoiding iatrogenic damage during endovascular treatments and decompressive surgeries.

We report an illustrative case.

\section{CASE}

A 53-years-old female patient had left cervical pain irradiating to the shoulder and arm. She was submitted to a magnetic resonance imaging (MRI) of the cervical spine to rule out disk pathologies, and the examination did not show disk alterations, but identified a loop of the left vertebral artery migrating to and widening the neural foramen at the $\mathrm{C} 3-\mathrm{C} 4$ level, causing bone

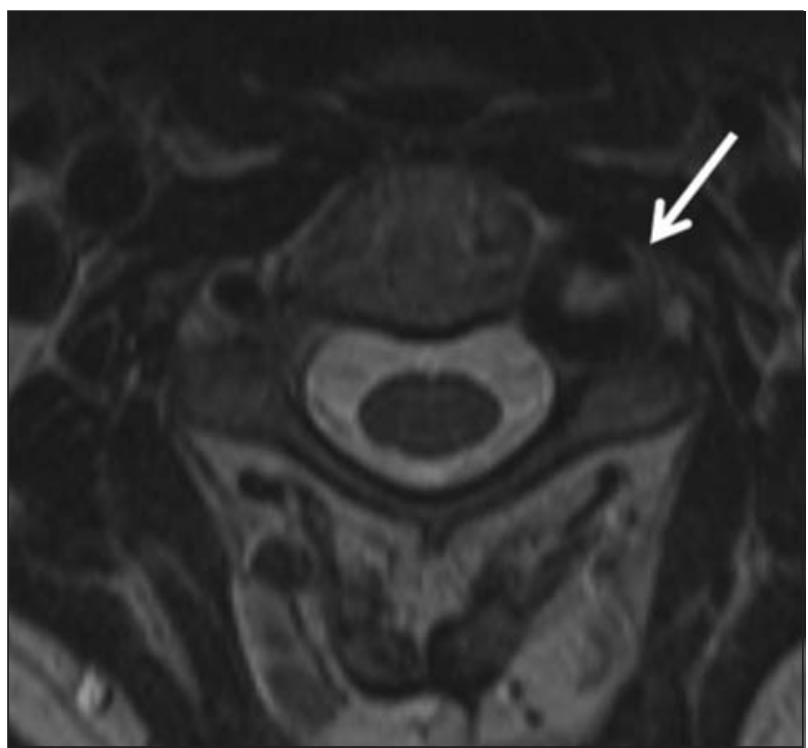

Fig 1. Axial T2 weighted magnetic resonance image at the $\mathrm{C} 3-\mathrm{C} 4 \mathrm{lev}$ $e l$, where the left vertebral artery loops into the neural foramen and causes its widening. Note that the widening is not concentric, it occurs in the anterior and superior direction. remodeling of the $\mathrm{C} 3$ vertebral body on its lateral and posterior aspect. This finding could explain her symptoms, although there were no signs of evident nerve compression (Fig 1). The exam was complemented with oblique radiographic incidences (Fig 2) and magnetic resonance angiography (tri-dimensional time of flight - 3D TOF) (Fig 3).

\section{DISCUSSION}

The widening of cervical neural foramen by a loop of the vertebral artery is a rare entity ${ }^{1}$, it was described by

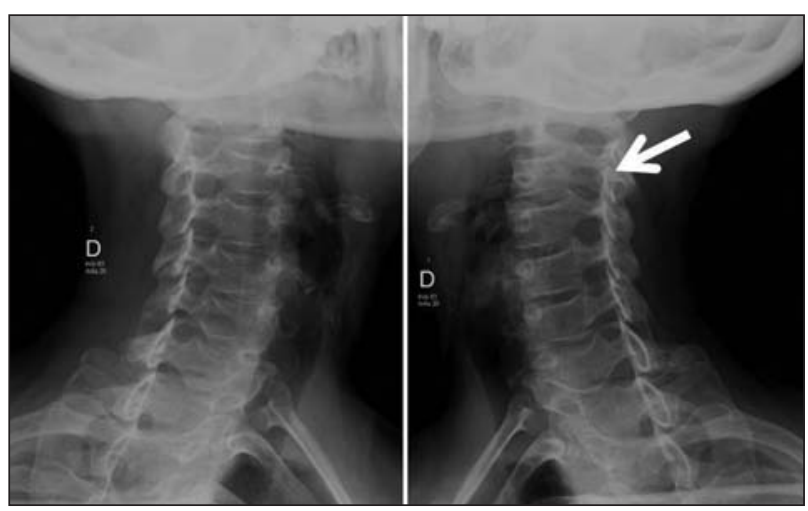

Fig 2. Radiographic oblique incidences of the neural foramina, showing the widening of the left $\mathrm{C} 3-\mathrm{C} 4$ neural foramen.

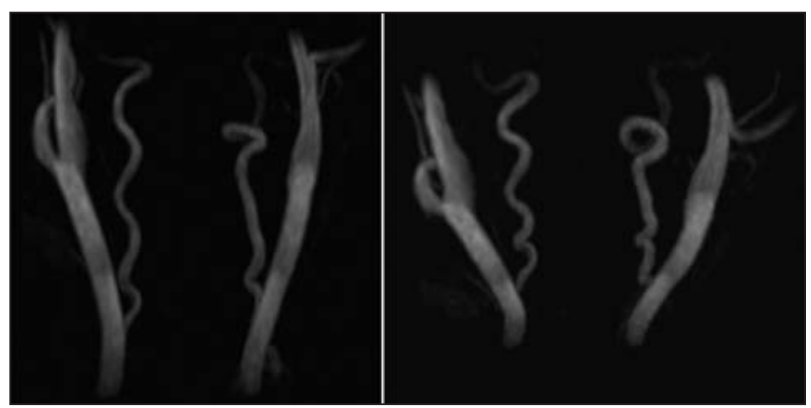

Fig 3. Tri-dimensional time-of-flight (3D TOF) showing the vertebral arteries and the loop in the left $\mathrm{C} 3-\mathrm{C} 4$ neural foramen.

\section{ALARGAMENTO FORAMINAL INTERVERTEBRAL POR ARTÉRIA VERTEBRAL TORTUOSA}

Médicos radiologistas da Clínica DAPI - Diagnóstico Avançado por Imagem, Curitiba PR, Brazil.

Received 18 August 2008, received in final form 12 November 2008. Accepted 13 December 2008.

Dr. Sergio Eiji Ono - Rua Brigadeiro Franco 122 - 80430-210 Curitiba PR - Brasil. E-mail: ono.sergio@gmail.com 
Hadley $^{2}$, based on autopsies. There is a range of differential diagnosis of widening of neural foramina, as tumors (neurofibroma, schwannoma, meningioma, metastases, plasmacytoma, malignant fibrous histiocytoma, osteoblastoma, chondrosarcoma, lung tumor), absence of a pedicle, lateral meningocele, aneurysm of an extracanial vertebral artery, spinal tuberculosis, and increased caliber and tortuosity of the vertebral artery due to increased flow associated with coarctation of the aorta.

The mechanism by which the vertebral loop forms and migrates into the intervertebral foramen is unclear ${ }^{3}$. The most common level of occurrence of widening of neural foramen by a tortuous vertebral artery is $\mathrm{C} 4-\mathrm{C}^{1,2}$, followed by C3-C4 level ${ }^{2}$. The most frequent side of occurrence is on the left ${ }^{2}$. The identification of a widened neural foramen is seen on a conventional radiography and on a computed tomography (CT) studies. The tortuous vertebral artery is recognized on Doppler ultrasound, on CT with endovenous (iodine) contrast media, and on MRI (seen as signal voids on the $\mathrm{T} 1$ and $\mathrm{T} 2$ weighted images), and on angiographic studies as 3D TOF. The widening occurs usually in a non concentric form ${ }^{4}$, helping the differentiation with widening caused by tumors.

Between $\mathrm{C} 2$ and $\mathrm{C} 6$ levels the nerve roots are close to the posterior aspect of the vertebral artery and its tortuosity can compress the roots. There are case reports describing radiculopathies secondary to the vertebral artery tortuosity ${ }^{4,5}$, but this is considered an exceptional cause of cervicobrachialgia. There is also a case report of a vertebral artery reconstruction in a patient with important symptomatology, with relief of the pain and no recurrence in a period of 2 years of follow-up ${ }^{3}$.

The loops and the tortuosity of the vertebral artery, causing widening of neural foramen, are asymptomatic on the majority of the cases according to the literature, and rarely are causes of cervical pain, but if not known by the radiologist and identified, it can lead to disastrous iatrogenies in endovascular treatments of intracranial arteries through vertebral arteries, or in decompression surgeries, when corpectomies are made, injuring this vascular structure.

In conclusion, a loop and the tortuosity of an extracranial vertebral artery, widening a neural foramen, is a rare entity and asymptomatic on the majority of the cases, but it must be considered in the differential diagnosis of widening of a cervical neural foramen, and as a rare cause of radiculopathy. If not identified in the imaging studies and reported to alert the surgeon it can cause iatrogenic lesions during surgical interventions.

\section{REFERENCES}

1. Kivrak AS, Koc O, Emlik D, Kiresi D, Odev K, Kalkan E. Differential diagnosis of dumbbell lesions associated with spinal neural foraminal widening: imaging features. Eur J Radiol, 2008 (in press).

2. Ekinci G, Baltacioglu F, Özgen S, Akpinar I, Erzen C, Pamir N. Cervical neural foraminal widening caused by the tortuous vertebral artery. Clin Imaging 2001;25:320-322.

3. Sakaida H, Okada M, Yamamoto A. Vascular reconstruction of a vertebral artery loop causing cervical radiculopathy and vertebrobasilar insufficiency: case report. J Neurosurg 2001;94(Suppl 1):S145-S149.

4. Maiuri F, Iaconetta G, Gallicchio B, Briganti F. Coiling of the vertebral artery presenting with neuralgic pain. Clin Neurol Neurosurg 1997;99: 56-59.

5. Horgan MA, Hsu FPK, Frank EH. Cervical radiculopathy secondary to a tortuous vertebral artery: case illustration. J Neurosurg 1998;89:489. 